\title{
Starting out in farming - ownership, goals and opportunities
}

Isabelle S. CRAWSHAW and Patrick R. CRAWSHAW

1285 Waihou Rd, RD6, Patoka 4186, New Zealand

Corresponding author: isabelle.crawshaw@outlook.com

\section{Setting the scene}

In August 2018, we purchased a 272-hectare pastoral and 8-hectare carbon farm in Patoka, Hawke's Bay approximately $40 \mathrm{kms}$ west of Hastings (Figure 1), from a retiring couple. The land is approximately $33 \%$ cultivatable flat to rolling country, with the balance largely medium and steep hill country. Over the first year of ownership, we have run trade lambs, breeding ewes, breeding cattle and trade cattle. As we move out of the establishment phase and into a more stable operating system, we will look to continue with a breeding cow and trade cattle policy that supports a winter lamb finishing programme. In this instance, the livestock enterprises will target a $30 \%$ breeding component with the remainder trading.

At the end of 2018, we put our names forward to be the Beef + Lamb Monitor Farm as we felt it would be a

fantastic opportunity to get a team of experts around us and draw on community knowledge to help ensure we put our best foot forward into farm ownership and maximise production while not jeopardising our passions.

As a young couple getting into farm ownership, we both work off farm to supplement the income and financial situation. Patrick works part time for Firstlight Foods NZ and Isabelle runs an Events and Marketing Contracting business, which is primarily based at home. We both work on farm as well as juggling offfarm work and extra-curricular activities.

\section{Getting into farm ownership}

Purchasing a farm and getting our feet onto our own piece of land has been a goal ever since leaving university. To help us achieve this, we both went straight into employment after graduating from Lincoln

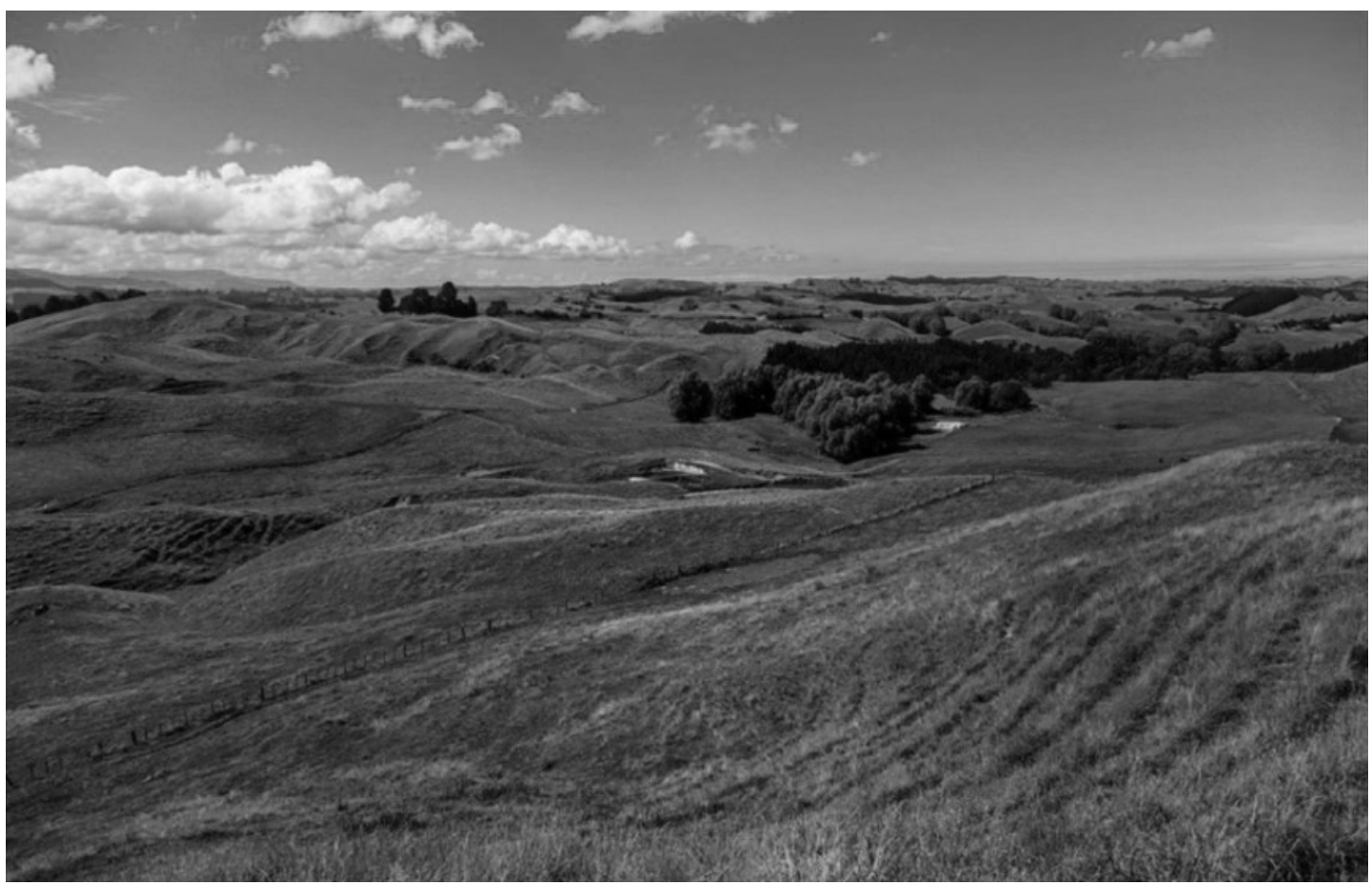

Figure 1 Looking across Patoka. 
University and created some personal budgets to allow us to save one full income each year for five years. Using our saved income and some family support, we were able to purchase a residential property in Christchurch which we rented out for three years to create some extra income.

We were both very lucky to go through University on scholarships, so we went into employment free from student loans.

When looking into purchasing the farm we did some really prudent budgets and had open and honest conversations with our bank manager about what we needed to do to achieve the financial grounding to be able to buy the farm. The transparency and rapport we have with our bank manager is a huge strength to our business right from the purchase process and ongoing, all which started many years prior to the investment to build their confidence in our ability. In securing the funds, the underpinning factors were that we both offered an off-farm income firstly and were able to source security from family.

This is what our final set-up was to get into farm ownership (Figure 2):

- Loan from the bank

- Loans from both Isabelle's and Patrick's parents at a set interest rate, which was less than what the bank was offering to make up the difference in equity

- Equity from selling the rental property in Christchurch and savings to purchase all the required stock and plant

- In addition, we share-farmed some stock with Patrick's parents

- The dual off-farm income means we don't take a large drawing out of the business and we can support its cashflow if need be to cover cost.

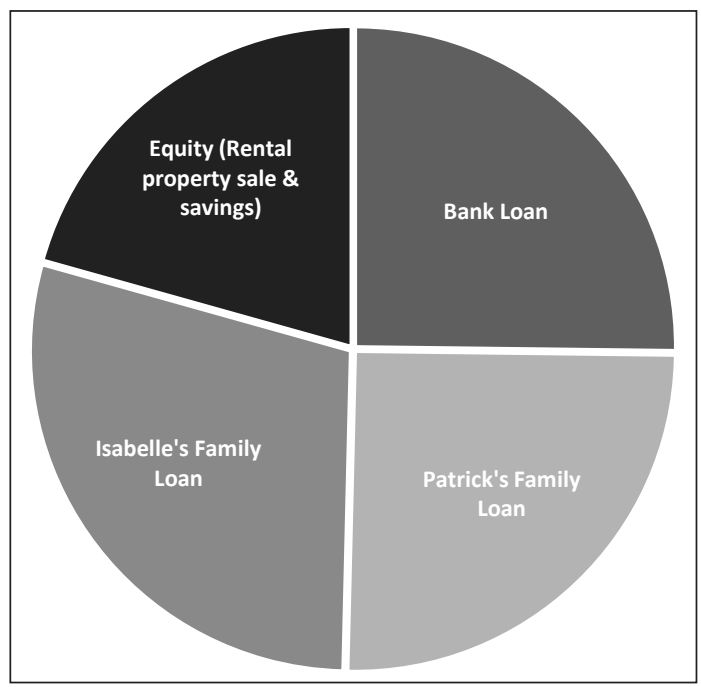

Figure 2 Breakdown of assets.
Table 1 Short-term goals (2-3 years).

ENVIRONMENTAL

- Comprehensive environment plan done by June 2019

- Provide adequate shade and shelter plantings in every paddock by 2021

- Accurate plan around our forestry in July 2019

FINANCIAL/PRODUCTION

- \$150k debt paid off by 2021

- $320 \mathrm{~kg} \mathrm{cwt} / \mathrm{ha}$ by end of programme

- $90 \%$ calving percentage by 2020

\section{STOCK}

- Fully stocked on farm by April 2019

- Own all the stock on farm by July 2019

- Registered breeding herd by November 2020

\section{Goal Setting}

Setting SMART (specific, measurable, achievable, realistic, timely) goals have always been a driver to help us shape our future direction and keep us accountable for getting to where we want to be. Once we got into farm ownership we set some new goals around the farming business, as well as realigned our personal goals to complement these. We broke our on-farm business goals down into three areas: environmental; financial/production; and stock. Beginning with some long-term (10-year) goals, we then broke them down into medium (5 years) and then short-term goals (2-3 years), which essentially set out an achievable timeline in reaching our long-term goals as the extension of these.

As we achieve our goals, we modify and update them to set the next benchmark of what we are wanting to achieve in that space. These are the goals that we set when we initiated the Monitor Farm Programme, and those highlighted bold have since been achieved and therefore updated (Table 1):

Alongside these, we have some more personal goals such as:

- Hosting at least one school group on farm every year

- Completing personal/professional development individually every year

- Taking at least 3-weeks' holiday off-farm every year. We both feel as though it is important to have both business and personal goals, and that they support each other.

\section{The Farm}

In purchasing $\mathrm{Te} \mathrm{Hau}$, we had some criteria on what the property needed to offer that we deemed important to our success. We wanted a property that had variation and suited both spectrums of intensive and relatively extensive agriculture. Patrick enjoys both prime and breeding stock coming from Kenhardt Angus in Nuhaka, hence the breeding cow herd as part of the livestock system. The portion of land suitable for cultivation was of interest also given the need for finishing power of 
prime stock and incorporating Te Hau into the family's property's in the Wairoa district. Underpinning our ability to work off farm is the reliable and high standard of infrastructure the property boasts. The property is well subdivided into an average paddock size of 5.6 ha (electrified for further cattle subdivision) with a reliable reticulation scheme providing troughed water in every paddock while still being supplemented by natural water. Finally, the base fertility, although an opportunity, provides a sound platform to execute productivity with reduced labour inputs from the outset. The limitation of the property given our off-farm commitments is its location relative to our off-farm workplaces with a 2-hour return commute on 'office days'.

One of our key goals to underpin the success of our farming operation is $320 \mathrm{~kg}$ CWT per effective hectare. This is a key performance indicator for us to ensure we are operating with efficiency and exceeding industryaverage productivity. As we are not on-farm full time, we see this as a moderate- to high-expectation goal and will look to improve on this once it is met, while not forgoing the balance of lifestyle we enjoy. Similarly, by focusing our attention on what we can control within the farm gate, we value our relationships outside the farm gate as is the case in partnering with PML and Atkins Ranch to do their part in securing the pricing outside the farm gate.

To fine tune and extrapolate Patrick's thinking, and to aid in achieving the three-year carcass weight goal for the business, Farmax modelling is employed to scenario through different propositions and ultimately identify challenges before they impact the profitability of the business. Farmax has been a great tool for providing accuracy in decision making and is another form of creating accountability within the business. With the distraction and distance created with off-farm employment, the modelling and recording system has proved an excellent aid for farm management.

We are under no illusion that even with our best efforts some goals may not be achieved but, as we understand the property, how it responds to the season and pasture development, greater clarity will be found in developing a robust system that will consistently perform to meet expectations. At that time we will recalibrate the goals and set the next achievements into the horizon.

\section{Monitor Farm Programme}

As mentioned earlier, at the end of 2018 we put our names forward to be the Hawke's Bay Beef + Lamb Monitor Farm and had our first community day in February 2019. This was an exciting initiative for us and the project as we were essentially starting off a blank canvas operating system. In putting together a network of people with a lot more experience and expertise than we have to help shape our farming operation from the outset was a no brainer. We also saw the opportunity it provides for the wider community, where by our colleagues can participate and see changes in action and talk with the respective experts whether it be fertiliser, forestry, agronomy, animal performance - the list goes on. The hope is that by seeing and believing, others will be willing to adopt appropriate practices to enhance their businesses.

So far we have had three community days on farm, each with an initial focus on environmental critical source areas, feed quality and our stock policy alongside Farmax. It has been an incredible experience to be a part of and we are looking forward to the remainder of the programme in developing a whole-farm system that meets our, our peers' and our consumers' expectations of sustainability on all three fronts (financial, environmental and social). 
